\title{
Nutrient-dense, pesco-vegetarian, affordable, low-calorie, and quick recipes support a reduction in climate impact of diets
}

\author{
Corné van Dooren \\ Netherlands Nutrition Centre (Voedingscentrum), The Hague, Netherlands
}

\begin{abstract}
Introduction

Educating cooking skills through applying healthy recipes is an effective intervention to stimulate healthy diets. The Netherlands Nutrition Centre applies this strategy by distributing recipes via websites, recipe books, and newsletters. The recipe database exists of 1891 recipes of which 1188 are main courses. In 2018, the recipes website was consulted through 338.598 unique pageviews. Healthier diets tend to be also more sustainable. This study analyses the climate impact of the recipes and its relationship with recipe characteristics.
\end{abstract}

\section{materials and methods}

1188 main courses were analysed on their popularity (top $100>500$ pageviews/y), climate impact, vegetarian or not, preparation time ( $<15$ minutes, $15-30 \mathrm{~min},>30 \mathrm{~min}$ ), price ('budget' $<€ 2.25 \mathrm{pp}$ ), kilocalorie content (low $<525 \mathrm{kcal})$ and nutrient density. The environmental impact was calculated by summing the greenhouse gas emissions (GHGE) of the ingredients $\left(\mathrm{CO}_{2 \mathrm{eq}-\mathrm{ingr}}\right)$ and of the energy used for preparation $\left(\mathrm{CO}_{2 \text { eq-prep}}\right)$, together $\mathrm{CO}_{2 \text { eq-tot }}$. Recipes with $\mathrm{GHGE}$ lower than $1300 \mathrm{~g} \mathrm{CO}_{2 \text { eq-tot }}$ were labelled as 'Klimaatkanjer' (climate topper). Nutrient density was estimated with the Sustainable Nutrient-Rich Foods index (SNRF). Differences between recipe groups (t-test and Chi-square) and regressions (ANOVA) between characteristics were statistically analysed.

\section{results}

The average GHGE of the recipes is per person $1365 \mathrm{~g} \mathrm{CO}_{2 \text { eq-ingr }}$ plus $200 \mathrm{~g} \mathrm{CO}_{2 \text { eq-prep }}\left(1566 \mathrm{~g} \mathrm{CO}_{2 \text { eq-tot }}\right)$. Popular recipes do not differ significantly from average $(1680 \mathrm{~g})$. 'Klimaatkanjer' ( 754 versus $2277 \mathrm{~g})$, vegetarian $(812 \mathrm{vs} 2132 \mathrm{~g})$, nutrient-dense (SNRF > 1 ; 1087 vs $1880 \mathrm{~g}$ ), fish (1483 vs $2604 \mathrm{~g}$ meat), budget (1312 vs $1695 \mathrm{~g}$ ), and low-calorie recipes (1486 vs 1653g) have significant lower GHGE. The longer the preparation time, the higher GHGE. Popular recipes are more often budget $(\mathrm{p}=0.01)$ and less often low-calorie $(\mathrm{p}=0.03)$, but they do not significantly differ in vegetarian $(p=0.14)$, 'Klimaatkanjer' $(p=0.15)$, nutrient density $(p=0.09)$, or preparation time $(\mathrm{p}=0.06)$. Recipes show a positive correlation between GHGE and kcal $(\mathrm{R}=0.313, \mathrm{p}<0.01)$, GHGE and protein content $(\mathrm{R}=0.508$, $\mathrm{p}<0.01)$, GHGE and saturated fat content $(\mathrm{R}=0.399, \mathrm{p}<0.01)$, and a negative between GHGE and $\mathrm{SNRF}(\mathrm{R}=0.188, \mathrm{p}<0.01)$. $90 \%$ of the healthy recipes has a positive SNRF, of which $36 \%$ SNRF $>1$.

\section{discussion}

Healthy recipes are supposed to have a lower climate impact than unhealthy ones. But the climate impact of diets can be further reduced by choosing and promoting recipes that are highly nutrient-dense (SNRF $>1)$, (pesco-)vegetarian, affordable $(<€ 2.25)$, low-calorie $(<525 \mathrm{kcal})$ and/or quick to prepare $(<15 \mathrm{~min})$. Promoting affordable recipes as intervention is most promising because they are already more popular among Dutch consumers.

\section{Conflict of Interest}

There is no conflict of interest 